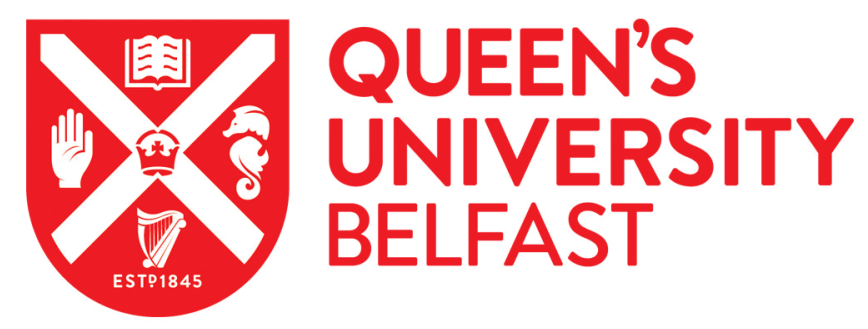

\title{
Structural performances of pultruded GFRP emergency structures - Part 1: Experimental characterization of materials and substructure
}

Cavaleri, L., Di Paola, M., Ferrotto, M. F., Scalici, T., \& Valenza, A. (2019). Structural performances of pultruded GFRP emergency structures - Part 1: Experimental characterization of materials and substructure. Composite Structures, 214, 325-334. https://doi.org/10.1016/j.compstruct.2019.02.004

Published in:

Composite Structures

Document Version:

Peer reviewed version

Queen's University Belfast - Research Portal:

Link to publication record in Queen's University Belfast Research Portal

Publisher rights

Copyright 2019 Elsevier Ltd.

This manuscript is distributed under a Creative Commons Attribution-NonCommercial-NoDerivs License

(https://creativecommons.org/licenses/by-nc-nd/4.0/), which permits distribution and reproduction for non-commercial purposes, provided the author and source are cited.

\section{General rights}

Copyright for the publications made accessible via the Queen's University Belfast Research Portal is retained by the author(s) and / or other copyright owners and it is a condition of accessing these publications that users recognise and abide by the legal requirements associated with these rights.

Take down policy

The Research Portal is Queen's institutional repository that provides access to Queen's research output. Every effort has been made to ensure that content in the Research Portal does not infringe any person's rights, or applicable UK laws. If you discover content in the Research Portal that you believe breaches copyright or violates any law, please contact openaccess@qub.ac.uk. 
Micro-tomography characterization of composite recycled glass-

\author{
silicone foams for their application in civil engineering \\ xxxx1, $\operatorname{xx\times x\times x\times 2,~} \mathbf{x \times x \times x \times 3}$

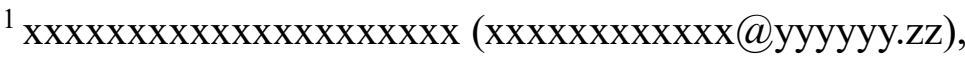 \\ ${ }^{2}$ xxxxxxxxxxxxxxxxxxxx (xxxxxxxxxxxx@yyyyyy.zz)

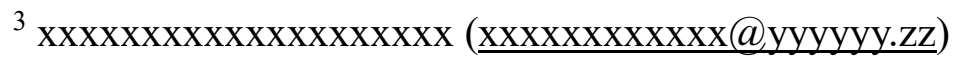

10 


\begin{abstract}
Non-invasive x-ray micro-computed tomography technique was applied for a complete quantitative and qualitative analysis of the cellular structure of composite foams constituted by a silicone matrix and a waste glass filler. Composite foams with different glass filler content in the range 0 wt.\%-80

25 wt.\% were synthetized and characterised. The tomographic analysis was employed in order to assess the structural heterogeneities, void fraction values and bubble size distribution for all composite foams. The 3D micro-CT images analysis, performed at different cross sections, highlighted heterogeneous cell growth or more elongated cells in low and high filler content foams, respectively. Batch with $60 \%$ of glass filler was identified as a composite foam with effective void fraction values 30 and relatively uniform spheroidal cellular structure (average sphericity 0.723 and diameter 0.107 $\mathrm{mm})$.
\end{abstract}

Keywords: silicone foam, waste glass, x-ray micro-computed tomography, foam structural analysis, morphometric parameters 


\section{Introduction}

Micro-computed tomography $(\mu-\mathrm{CT})$ is a non-destructive technique based on the use of reconstruction algorithms applied on X-ray scans. This analysis method allows to obtain 3 directional clouds of information that can be displayed as 3D images and 2D section that can be manipulated and

40 qualitatively and quantitatively analysed [1-4]. Even if $\mu-\mathrm{CT}$ is a precise technique, the final resolution depend on the scan parameters (e.g., tilt angle, number of scan, relative distance between the sample, the X-ray source and detector), the is affected by experimental limitations and artefacts are intrinsic in the reconstruction results $[5,6]$.

In material science, $\mu-\mathrm{CT}$ is used for the assessment of the morphometric [7,8] or mechanical [9] properties of material and to microscopically assess the actual sample geometry and identify geometrical parameters affecting the mechanical behaviour of the samples [10].

The tomographic technique has been proposed in the literature for the analysis of different types of cellular materials. This technique has been widely applied to evaluate the cellular structure of metal foams [11-14]. Likewise, significant applicative potentials have been also experienced in polymer foams [15] [16] [17], including polyurethane [18], polyethylene [19], polystyrene [20].

A significant aspect is the possibility to distinguishing three-dimensionally the foam cells population by parameterizing their size, shape and spatial location, making this technique stimulating in engineering design, process optimization and quality control.

Lightweight materials are increasingly used in civil engineering, by using several lightweight filling materials, for ever-larger applications such as cellular cemented clays [21] or concrete [22].

In recent years, significant interest has been found in the development of foamed materials with the use of waste materials for engineering applications [23] [24].

A strong point of the use of recycled products is that there give a positive impact on energy consumption and also limits the opening of new quarries for the production of new aggregates. To reach an effective eco-sustainability, various industries and end-users are sensible to new cleaner 
production of waste materials and consider recycled materials as a resource rather than a waste material destined for landfills.

In this context, glass-based cellular materials have been developed with promising results for structural and insulating applications [25,26]. Life Cycle Assessment (LCA) has been used effectively to highlight and quantify the eco-efficiency of waste glass recycling chain by identifying engineering solutions for sustainability thanks to the development of new products to be used in energy buildings efficiency [27] [28]. However, the use of recycled glass to produce lightweight cellular foams is still not yet mature to make cost-effective its use as a lightweight aggregate construction material.

The aim of this work is to evaluate the synthesis and morphological characterization of ecosustainable composite foams consisting of a siloxane matrix and glass waste filler as a future application in thermal insulation panels for civil engineering. The high chemical compatibility of the siloxane compounds with different fillers typologies has allowed to assess the applicability of this composite material, with promising results, in various fields of application [29-31]. In this concern, the glass filler has a good chemical compatibility with the silanol groups present in the silicone matrix [32]. The strong chemical interaction between the two components is a stimulus to identify their potential effective combination aimed obtaining a performing composite material in terms of physical-mechanical properties. For this purpose, a fundamental topic is offered by the morphology of the cellular structure of the composite foam which plays a key role in the durability and stability of the foam itself [33]. The definition and discrimination of the main morphometric parameters of the foam and how these vary according to the synthesis conditions is relevant aspect that need to be investigated in order for an its optimization during the experimental research and development.

For this class of materials, the Micro-computed tomography is able to discriminate the porosities inside the composite matrix providing reliable information about the cell structure by morphometric parameters performing specific software data analysis [34-36]. However, due to the intrinsically difficulties on the technique, attention must be paid for a correct identification of cell walls, cellular 
segmentation by using suitable threshold values on the histogram of the intensity of a grayscale image) avoiding software mistake in the reconstruction [37-39].

In such a context, in this work, $\mu$-CT was used to evaluate the influence of the amount of filler on the foaming dynamic in glass-silicon composite foams. The X-ray micro-tomographic imaging was assessed as suitable technique to give valuable and accurate information concerning the cellular structure of the composite foam in order to acquire more in-depth insights on changes in cell morphology induced by different filler content in the foam formulation. 3D tomography images were applied to acquire better knowledge on cell coalescence and cell collapse phenomena occurring during the foaming and their effect on cellular structure. Furthermore, thorough morphometric characteristics, among all composite foams, including porosity, dimension, distribution and shape of the cells were discussed.

\section{Material and Methods}

\subsection{Glass particles}

The glass filler was obtained as secondary raw material from the manufacturing prcess (i.e., sawing dust) of glass plates. The material received from the manufacturing plant was properly washed in distilled water and dried at $120^{\circ} \mathrm{C}$ for $24 \mathrm{~h}$ to eliminate the residual moisture through a vacuum oven. The resulting glass dust was sieved to obtain an homogenous distribution of the dimensions of the particles (i.e., between 53 and $125 \mu \mathrm{m}$ ).

\subsection{Foam synthesis}

Recycled glass filled silicone foams were prepared by using an open to air mould foaming technique. A Poly(dimethylsiloxane-co-methylhydrosiloxane), trimethylsilyl terminated, PMHS (M.W. 5,5006,500 CAS: 68037-59-2) and a silanol terminated polydimethylsiloxane, PDMS (M.W. 110,0000 CAS: 70131-67-8), both supplied by Gelest Inc., Morrisville, USA were used as matrix. Tin(II) 2ethylhexanoate $(\operatorname{Sn}(\mathrm{II}))(\mathrm{d}: 1.12$, M.W. 405.11, 50\%, CAS. 301-10-0) was used as catalyst. The foam 
preparation was performed, at first dispersing glass filler, under agitation for about $60 \mathrm{~s}$, in polydimethylsiloxane (PDMS) compound. Ethanol and water were added as solvent in order to reduce viscosity and easy obtain an homogenous slurry. Afterward, the polymethylhydrosiloxane (PMHS) was added to the mixture (PDMS/PMHS ratio 1:2) and vigorously mixed for 15s. Eventually, the tin catalyst was added, still under vigorous mixing, for about $15 \mathrm{~s}$. The so obtained slurry was poured into an open cylinder shaped mould. Foaming process was favoured by heating at $60^{\circ} \mathrm{C}$ for $24 \mathrm{~h}$ in order to complete the siloxane crosslinking according to the following reaction [40]:

$$
\equiv S i-O H+H-S i \equiv \rightarrow \equiv S i-O-S i \equiv+H_{2} \uparrow
$$

The blowing process is due to formation, during the reaction between hydride and hydroxyl groups of siloxane compounds, of the gaseous hydrogen product. Foams with different amount of glass filler, in the range 20-80 wt. \% of siloxane matrix (PDMS+PMHS), were made. A list of all compound amounts and glass filler content are reported in table 1. As reference, an unfilled silicone foam was considered (GF-0).

Table 1 - Siloxane solution compositions for different glass content

\begin{tabular}{|c|c|c|c|c|c|c|c|c|}
\hline & & & & & & & \\
\hline & & $G F-0$ & $G F-20$ & $G F-40$ & $G F-50$ & $G F-60$ & $G F-70$ & GF-80 \\
\hline PDMS & Siloxane & $42.6 \%$ & $36.8 \%$ & $29.7 \%$ & $26.0 \%$ & $21.7 \%$ & $17.2 \%$ & $12.0 \%$ \\
\hline PMHS & Siloxane & $21.3 \%$ & $18.6 \%$ & $14.9 \%$ & $13.0 \%$ & $10.9 \%$ & $8.6 \%$ & $5.8 \%$ \\
\hline Ethanol & Solvent & $14.9 \%$ & $12.6 \%$ & $10.3 \%$ & $9.0 \%$ & $7.7 \%$ & $6.1 \%$ & $4.5 \%$ \\
\hline Water & Solvent & $10.6 \%$ & $9.0 \%$ & $7.4 \%$ & $6.5 \%$ & $5.4 \%$ & $4.3 \%$ & $3.2 \%$ \\
\hline $\mathrm{Sn}(\mathrm{II})$ & Cathalyst & $10.6 \%$ & $9.0 \%$ & $7.4 \%$ & $6.5 \%$ & $5.4 \%$ & $4.3 \%$ & $3.2 \%$ \\
\hline Glass & Filler & $0.0 \%$ & $14.0 \%$ & $30.3 \%$ & $39.0 \%$ & $48.9 \%$ & $59.5 \%$ & $71.3 \%$ \\
\hline \multicolumn{2}{|c|}{ Glass/Foam [\%] } & $0.0 \%$ & $20.0 \%$ & $40.0 \%$ & $50.0 \%$ & $60.0 \%$ & $70.0 \%$ & $80.0 \%$ \\
\hline
\end{tabular}


Micro-computed tomography ( $\mu$-CT) was chosen as technique to assess the morphological properties of the analysed composites glass-silicon foams. An high-resolution micro-CT, SKYSCAN 1272 by Bruker (United States) was used to make X-ray scans. Taking into account the good rotational symmetry of the sample, to obtain acceptable data, the rotation step angle was set equal $0.4^{\circ}$ up to a total rotation of $180^{\circ}$. The accelerating voltage and the current flow were set to $60 \mathrm{kV}$ and $100 \mu \mathrm{A}$. A $0.11 \mathrm{~mm}$ cupper filter was used to enhance the image contrast. The acquired scans were post processed to obtain a $3 \mathrm{D}$ image. The resulting images resolution is equal to $21.73 \mu \mathrm{m} / \mathrm{pixel}$.

\subsection{D Image processing}

The acquired data and the reconstructed images were processed by applying digital filters to enhance the image quality and reduce the intrinsic noise that is peculiar for this technique. In particular, misalignment compensation, beam hardening correction, smoothing and ring artefact reductions algorithm were applied by the use of the software NRecon by Bruker (United States).

140 The so obtained dataset were than post processed by the use of the software CTAn by Bruker (United States) to obtain quantitative data by performing both 2D and 3D analyses. In this phase, further digital filters were used to reduce image noise by taking into account the real preview morphology of the samples (i.e., the images were de-speckled by eliminating pixel agglomerates smaller than 15 pixels). In particular, in order to characterize the cell foam structure and to obtain the cell foam

145 features, the following procedure was applied: median filtering of grey-scale images, segmentation by threshold, border killing (removal of the pores touching the borders of the image and, finally, calculation of cell features.

\section{Results and Discussion}




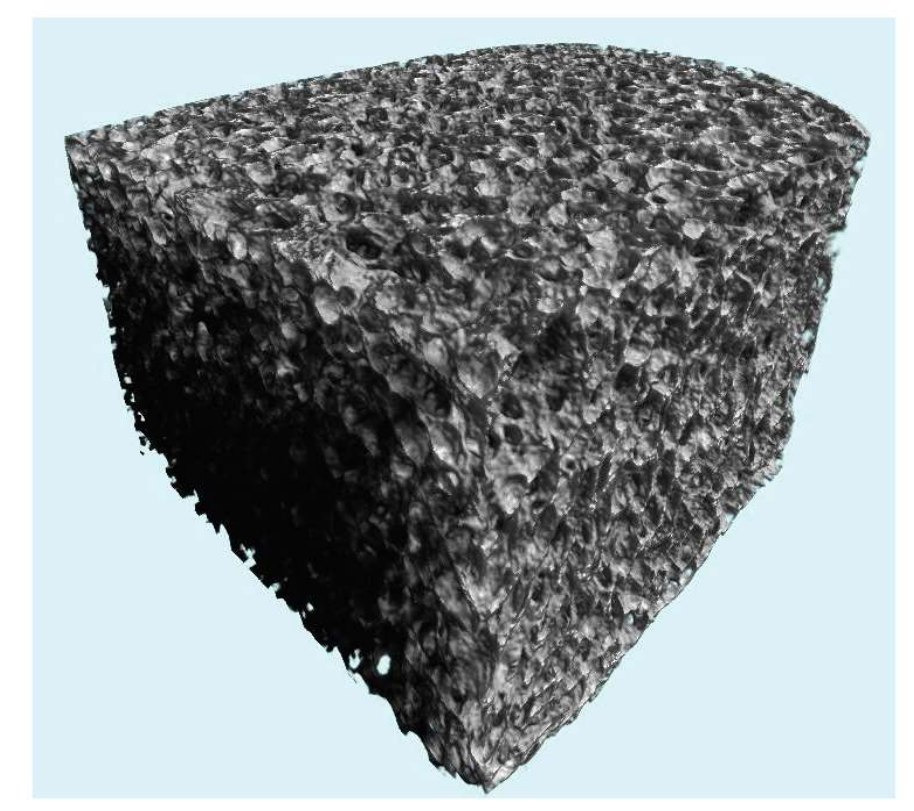

Figure 1 - example of a 3D Reconstruction (glass foam loaded with $20 \%$ of filler

The 3D tomography structure of a reference composite recycled glass foams with $20 \mathrm{wt} . \%$ of filler content, as obtained after image post-processing, is reported in Figure 1. In order to better visually evaluate the foam morphology, the 3D image was obtained generating a virtual cut along the foaming axis of the sample. The sample is characterized a relevant poly-dispersity, indicating that several phenomena occurring during the foaming stage.

The glass filled silicone foam is characterized by not regular circular shaped structure with a mixed open/closed cell morphology. Some small and narrow openings (cell windows) were identified ensuring an interconnection among cells. The cell walls (struts) are dense and compact and the overall structure seems to be without defects. 


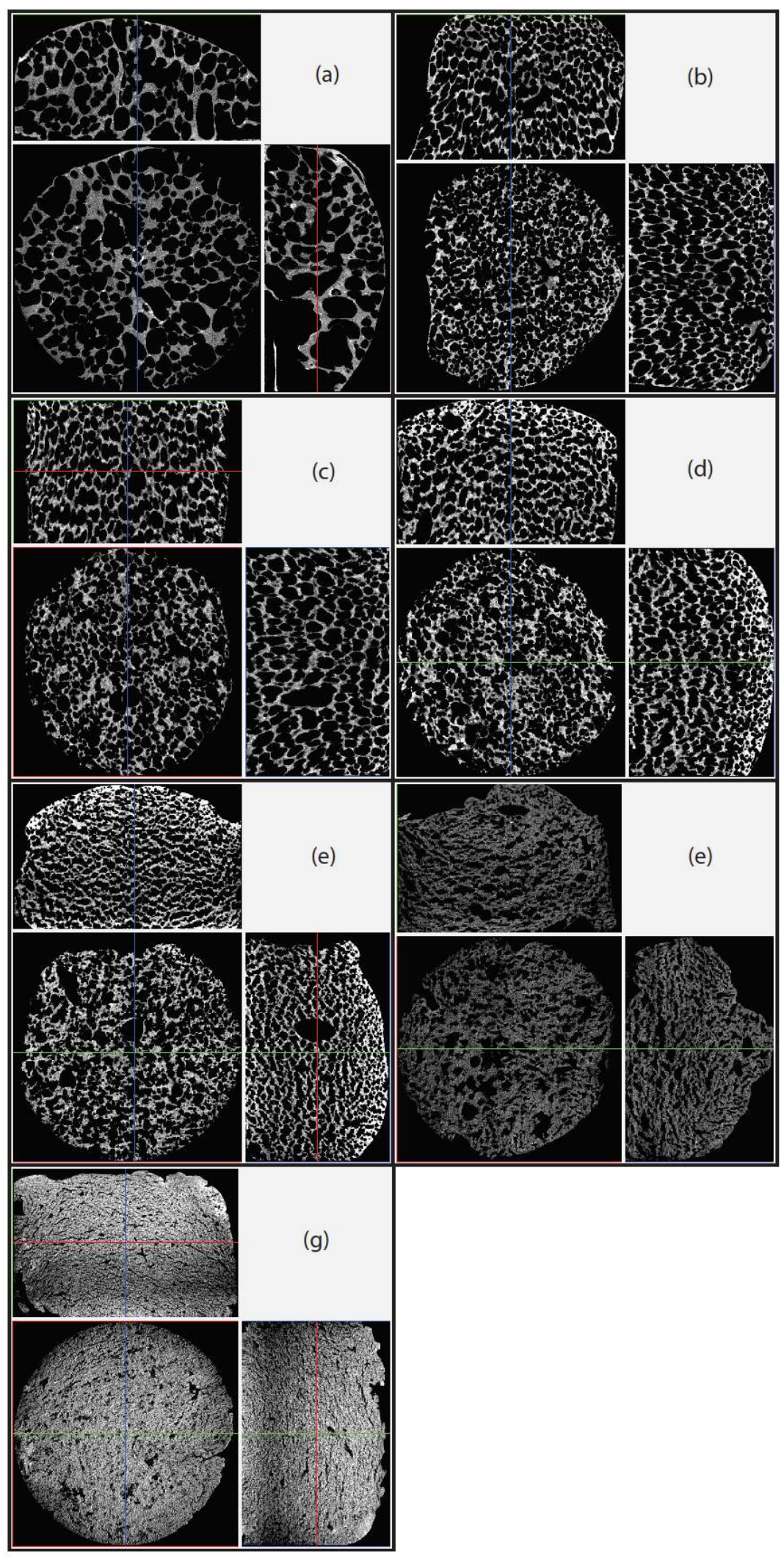

Figure 2 - Transaxsial (lower left images), sagittal (right images) and coronal (top images) sections for 165 increasing glass content: (a) 0 wt.\%; (b) 20 wt.\%; (c) 40 wt.\%; (d) 50 wt.\%; (e) 60 wt.\%; (f) 70 wt.\%; (g) 80 wt.\%. 
In order to better highlight the effect of filler addition on the cellular microstructure of the foam 2D slices in the reference planes of all foams with increasing glass content are shown Figure 2 . At increasing filler content is qualitatively visible a progressive reduction of bubble dimension.

In all composite foams a well structured morphology without macroscopic defects can be identified. Only for samples at higher glass filler content (GF_70 and GF80) some randomly internal cracks are shown, probably related to large amount of filler in the structure that favors the adhesion reduction at the filler/matrix interface. All samples evidenced a quite regular cell geometry both in longitudinal and transversal directions. The cell size distribution is almost homogeneous mainly at low filler content foams. However, it can be shown some heterogeneities on composite foams increasing the filler content in the foam formulation, as evidenced by local large size bubbles or voids in the structure, indicating a possible bimodal distribution of the cells.

From a structural point of view, at low zeolite content, each cell appears to be well interconnected each other pointing out the presence of possible structured three-dimensional pathways. The cell walls are thin and compact. As previously discussed, these foams are characterized by an open/closed cells structure with narrow opening windows that guarantee the connection among neighboring cells. Due to the alrge bubble interconnection the bubble shapes appear not regular or spheroidal.

The bubble growth process in the silicone matrix occurs cause to nucleation of gas bubbles in the siloxane compounds during the condensation process, according to eq.1. Subsequently, the bubbles, during the foaming stage, grow up, interact and coalesce each other inducing a wider dispersion in the cell size [41].

These composite foams are characterized by a relevant foaming ratio (defined as initial to final foam volume ratio) with large and homogenously distributed bubbles in the whole sections. The large foaming ratio can be related probably to coalescence phenomena occurring among bubbles that produces large volume bubbles. Furthermore, the bubble size increase could be due to the gas phase expansion in the silicone foam considering that the pressure decreases along the flow direction. During the foaming, due to friction pressure losses, the pressure along the flow direction is lower than 
the previous condition. This exerts lower pressure acting on the gas bubbles wall, favoring the expansion of the bubbles [42]. However, at increasing glass filler content the viscosity of the synthesis slurry progressively increases heavily limiting coalescence phenomena. The bubble not grow up and the obtained composite foam is mainly constituted by small, regular and spheroidal bubbles well distributed in the filled foam structures (GF-50 and GF-60).

A homogeneous and regular distribution of the bubbles, for the foams characterized by intermediate filler content, indicates that the foaming process is still effective. However the coalescence phenomenon of the bubbles is progressively regressing due to the gradual increase in viscosity of the slurry which has also a limiting action on the ratio of foaming [25].

For very high composite foams (GF-70 and GF-80) this phenomenon become significant due to the very high viscosity of the composite synthesis slurry. This promotes the bubble break-up caused by the increased viscous force acting on the growing bubbles and also hinder the coalescence phenomena due to drainage of the film at the interface that require more time [43]. Furthermore, during the foaming evolution, the viscosity of the glass-siloxane slurry progressively increases due to occurring crosslinking reaction that favors gas cells shrinkage [44]. Moreover, the presence of glass powder in the siloxane based slurry could influence the foaming kinetics due to chemical interaction between constituents. The glass filler is constituted by surface hydroxyl groups that are able to interact with the hydroxyl terminated and hydrated groups of the siloxane compounds, similarly to dehydrogenative coupling reaction between siloxanes molecules [45]. Therefore, an increase in the kinetic reaction can be identified coupled with a higher hydrogen evolution (as reaction product of glass-siloxane coupling). Eventually, the foaming ratio appears to be very low, e.g. for GF-80 samples, the foaming process is not stable and an average foaming ration of about $25 \%$ was achieved.

215 The cellular foam structure is very dense and compact although several internal macro- and microporosity can be identified. The bubbles are characterized by a depressed ellipsoidal shape (due to their collapse during the foaming stage because the high slurry viscosity) and are not interconnected each other indicating that this foam structure is instable and with low cohesion strength. 
Starting from digital analysis on 3D tomographic images a statistical and morphometric parameters discrimination for each sample was carried out to better investigate the influence of the glass filler addition on the morphological properties of the composite foams. Some statistical parameters are reported in Table 1.

Table 1: statistical parameters of bubble size distribution at varying glass filler content

\begin{tabular}{|c|c|c|c|c|c|c|}
\hline & $\begin{array}{c}\text { Average Diameter } \\
{[\mathrm{mm}]}\end{array}$ & $\begin{array}{c}\text { SD } \\
{[\mathrm{mm}]}\end{array}$ & $\mathrm{CoV}$ & Sphericity & Anisotropy & $\begin{array}{c}\text { Void volume } \\
\text { fraction }\end{array}$ \\
\hline GF-0 & 0,173 & 0,226 & 1,308 & 0,667 & TOMMASO & TOMMASO \\
\hline GF-20 & 0,128 & 0,096 & 0,749 & 0,669 & $\mathrm{xx}$ & $\mathrm{xx}$ \\
\hline GF-40 & 0,101 & 0,074 & 0,733 & 0,691 & $\mathrm{xx}$ & $\mathrm{xx}$ \\
\hline GF-50 & 0,110 & 0,082 & 0,747 & 0,695 & $\mathrm{xx}$ & $\mathrm{xx}$ \\
\hline GF-60 & 0,107 & 0,073 & 0,685 & 0,723 & $\mathrm{xx}$ & $\mathrm{xx}$ \\
\hline GF-70 & 0,075 & 0,038 & 0,508 & 0,715 & $\mathrm{xx}$ & $\mathrm{xx}$ \\
\hline GF-80 & 0,069 & 0,044 & 0,637 & 0,683 & $\mathrm{xx}$ & $\mathrm{xx}$ \\
\hline
\end{tabular}

Standard deviation (SD) was used to measure of the dispersion of a set of data from its mean. However considering that datasets are characterized by different means, coefficient of variance $(\mathrm{CoV})$ was also used as statistical parameter to evaluate the variability of spread of data. It is defined as the standard deviation $\sigma$ to the mean value $\mu$ percentage ratio. The sphericity is defined as the ratio between the surface area of a sphere with the same volume of the bubble and the real surface area of the bubble. By definition, a sphere has sphericity equal to unity. Analyzing the statistical parameters, it is possible to evidence that increasing glass filler content a gradual reduction of composite foaming taken place as highlighted by the progressive reduction of average diameter of bubbles and total void volume fraction. A transition from low density to compact composite foams occurred at about $60-70 \mathrm{wt} . \%$ of glass content. This aspect was confirmed by the evolution of CoV at increasing 235 glass amount. Lower CoV values are observed at for GF-70 sample. For the composite foam with low glass content, the coalescence phenomenon plays an important role on bubble growth inducing a high COV. Instead, 
at intermediate glass content the coalescence is significantly inhibited and a homogenous distribution of bubbles can be identified (low $\mathrm{CoV}$ ). Finally, for high glass content, the cellular structure of the foam is structurally limited, the low adhesion and cohesion induces a heterogeneous distribution of small size bubbles with subsequent slightly higher $\mathrm{CoV}$.

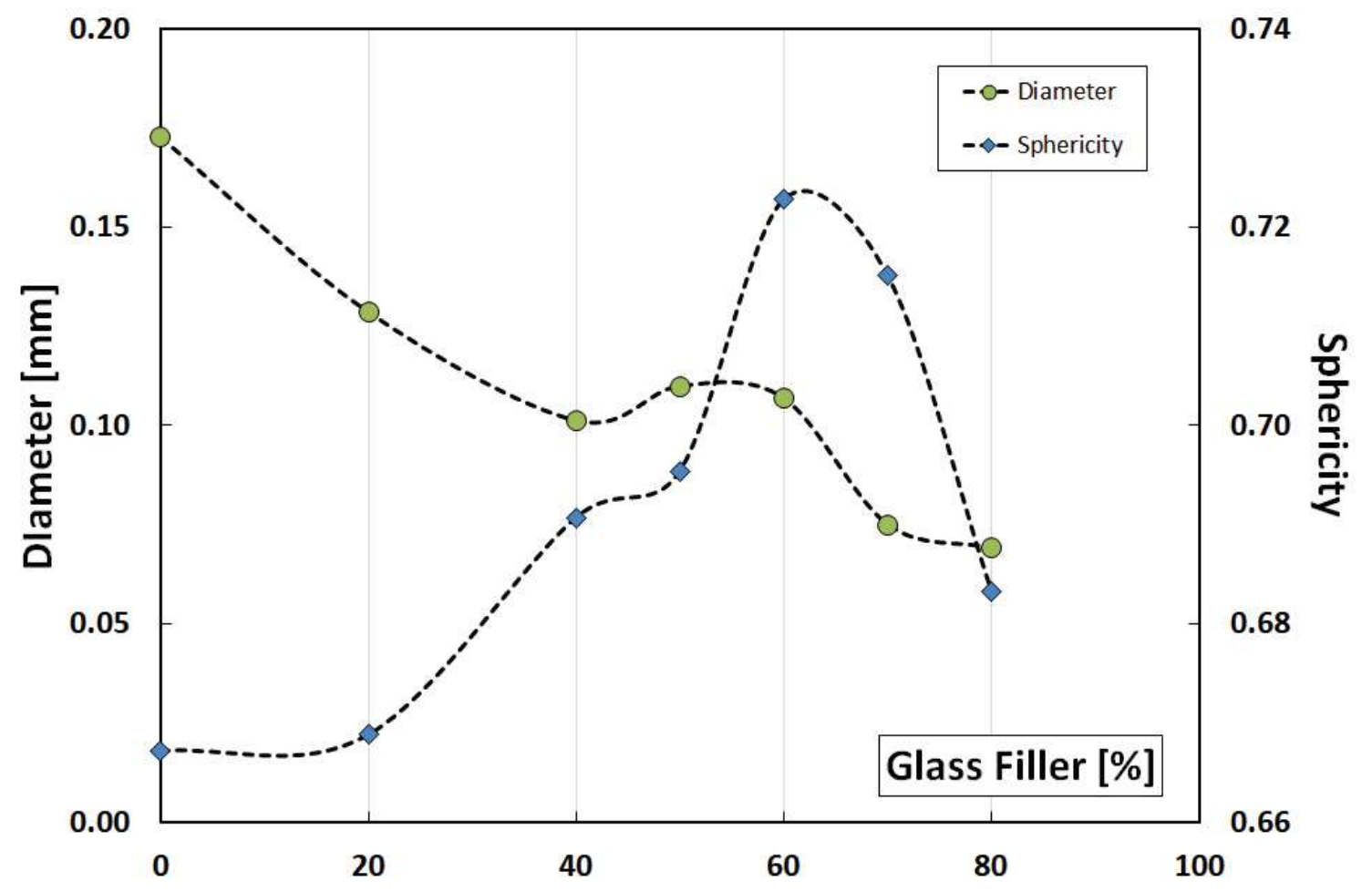

Figure 3 - Average cell size diameter and sphericity at increasing glass filler content

245 Further relevant consideration can be evaluated analyzing Figure 3 that summarizes the trend of average bubble size diameter and sphericity at varying glass filler content. The average bubble size diameter decreases at increasing glass filler amount in the composite foam. In fact, after $40 \%$ of glass content addition a reduction of about $60 \%$ of bubble size diameter has been observed. Afterward a slight stabilization at intermediate filler content (40-60 wt.\% of glass filler) can be identified. In this range the average cell diameter was about 0.1 $\mathrm{mm}$. Afterward at very large filler content a progressive and significant reduction of bubble dimeter occurred reaching a minimum for GF- 80 sample (bubble diameter $0.065 \mathrm{~mm}$ ). Concerning the sphericity parameter, a maximum at a filler content of $60 \%$ can be observed. This can be explained by considering that at first at low 
glass content foam bubbles can start the coalescence process. Thus, when the siloxane matrix completed the crosslinking process interconnected voids with complex geometry (therefore, low circularity) can be highlighted. Conversely, at increasing glass content in the composite foams the coalescence phenomenon is triggered. When the foam solidification is completed a very large amount of bubbles not interacted each other inducing a lower interconnected structure and therefore small bubbles of spheroidal shape were predominant. With very high glass powder, content few bubbles are able to coalesce due to the high viscosity of the formulation. At the same time, the bubbles start to collapse under the foam generating ellipsoidal shaped bubbles with long axis orthogonal to gravity direction. Eventually, small size with a low sphericity bubbles were mainly observed.

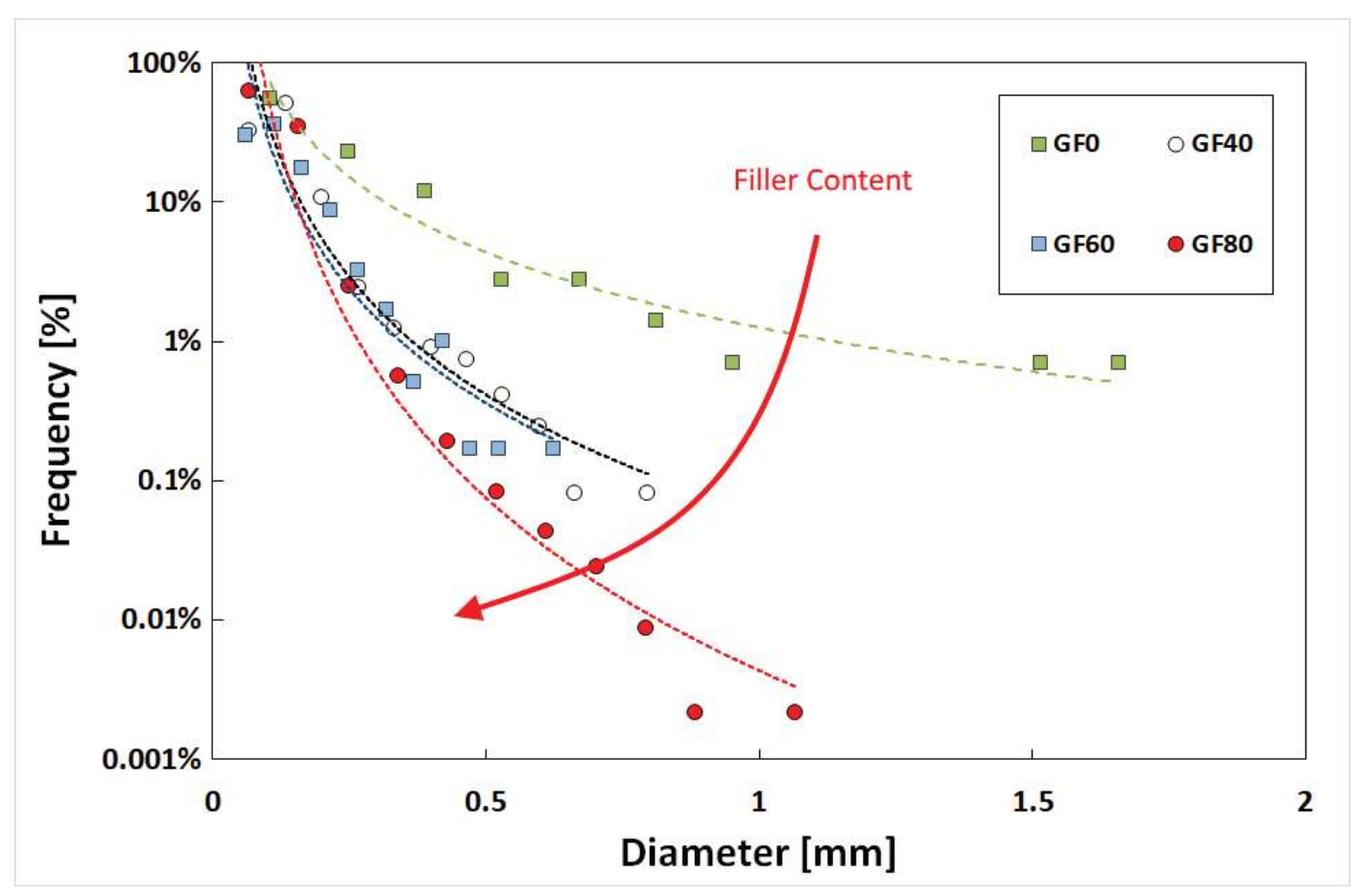

Figure 4 - Frequency distribution of cell size diameters for four reference composite foams at varying glass content.

265 Figure 4 shows the frequency distribution of cell size diameters for three reference composite foams at varying glass content. The $\mathrm{Y}$ axis is the fraction in percentage of bubble counts with a specific diameter cell size (determined on 3D volume analysis), within a particular bubble size range denoted by $\mathrm{X}$ axis. At increasing filler content, a progressive increase of amount of small size pores can be observed. Unfilled foam showed a broad cell size distribution (about 0.2-1.8 mm). A significant variation in cell size distribution can be identified 
270 for unfilled foam, where the non-homogenous cellular morphology was previously qualitatively highlighted from the 3D images. On the other hand, the presence of glass powder in the foam implies an evident thinning of the bubble size range in the foam microstructure. In particular, all foams loaded with glass showed a maximum bubble diameter of about $1.0 \mathrm{~mm}$.

An important aspect that needs to be assessed is to define how the volumetric porosity of the foam is related 275 to specific bubble sizes and then indirectly acquire useful information to assess how this one affects the morphology of the foam itself. The volumetric porosity can be defined as the ratio of the volume of the bubbles (voids) with the apparent volume. Consequently, it is possible to divide this contribution into sub-classes based on bubble size diameters, according to the following relation:

$$
V_{i}(\%)=\bar{V}_{i} \cdot n_{i} / V_{B} \quad \text { Eq. } 2
$$

Where $\bar{V}_{i}$ is the average volume of a particle with a diameter $\mathrm{d}_{\mathrm{i}} . \mathrm{n}_{\mathrm{i}}$ is the number of bubbles classified with this 280 diameter. $\mathrm{V}_{\mathrm{B}}$ is total volume of bubbles. $\mathrm{V}_{\mathrm{i}}(\%)$ is the volume percentage of bubbles with i-class diameter. 


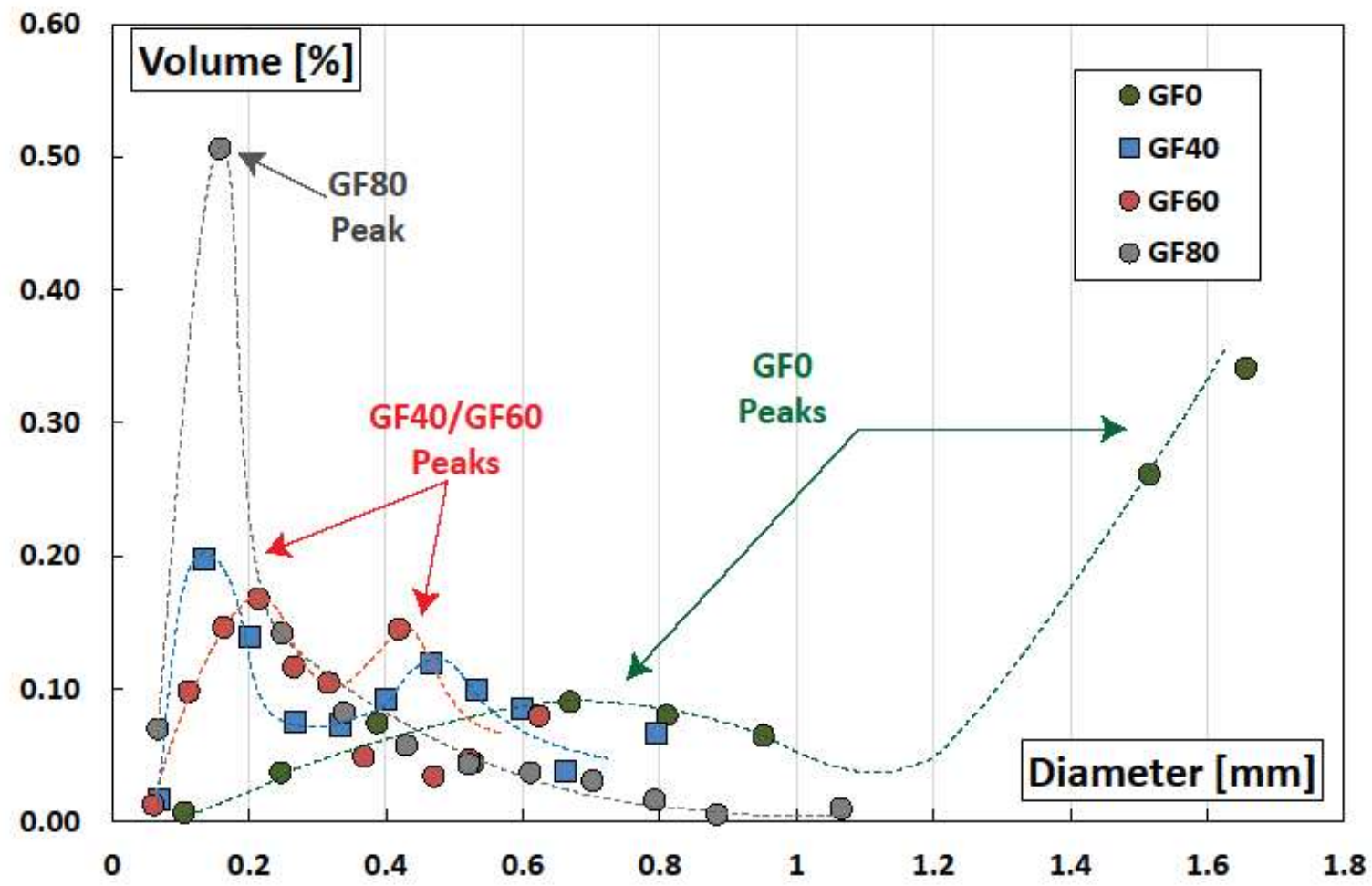

Figure 5 - Frequency plot of volume bubble at varying diameter for four reference composite foams at varying glass content.

This index represents a reliable parameter to evaluate if a given class of diameters affects the total foam porosity. A high index for the i-th class identifies a high incidence of this bubble size diameter range. Figure 5 summarizes the volume bubble fractions at increasing diameter range for some reference composite foams. Analyzing the distribution modification at varying filler content some considerations can be extrapolated. The distribution frequency of diameter size of unfilled sample is characterized by wide and less pronounced multipeak shape. Vice versa, at increasing glass content, the distribution tends to become increasingly high and narrow, with a skewness effect more and more concentrated at lower diameters. In particular, for GF-0 batch a bimodal distribution can be observed. A first peak occurs in the size range 0.6-0.8 $\mathrm{mm}$. Furthermore, a second relevant peak above $1.6 \mathrm{~mm}$ diameter was identified. This second peak can be associated with coalescence of and interconnection phenomena of different bubbles originated during the foaming stage. Aggregation is facilitated by the low viscosity of the slurry due to the absence of filler.

By increasing the glass filler content there is a progressive shift of such peaks towards smaller diameters. In particular for the GF-60 foam, the porosity distribution in the composite foam is still clearly bimodal, although 
the diameters associated with the two peaks are strongly lower $(0.2$ and $0.4 \mathrm{~mm}$ for the first and second peak, respectively) than unfilled foam. This aspect is related to the progressive reduction of coalescence phenomena for composite foams at higher glass content. In fact, the peak magnitude observed at large diameter size in GF0 sample decrease progressively up to disappears for GF-80 samples, where coalescence phenomena is heavily limited.

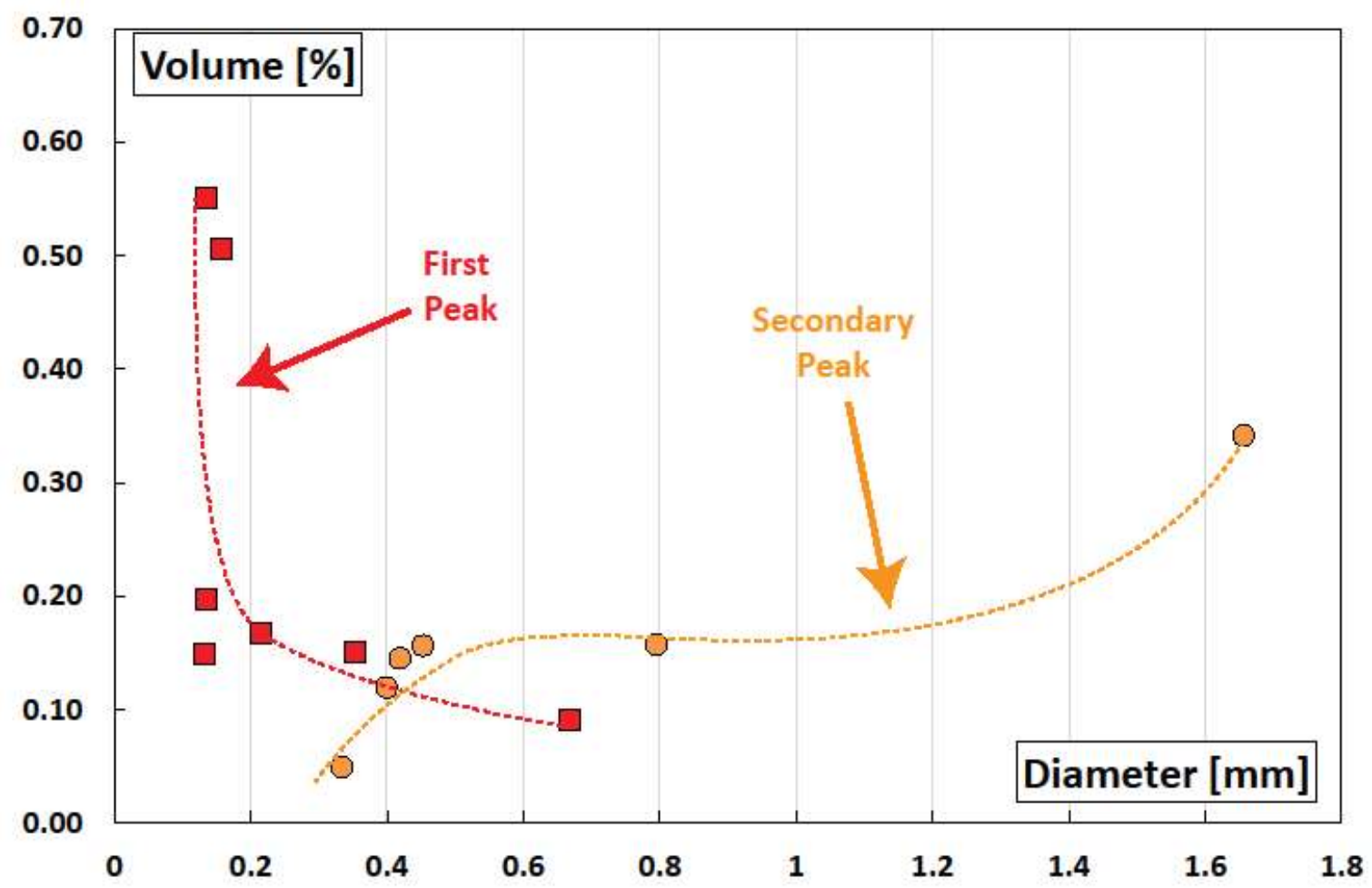

Figure 6 - Trend of first and secondary peak of volume bubble frequency at varying diameter.

These considerations are summarized in Figure 6, where the trend of first and secondary peaks observed in Figure 5 for all the composite foams at varying glass filler content is reported. It is clearly evident the secondary peak decrease significantly at increasing filler content. Conversely, a progressive increase in magnitude toward lower diameter can be highlighted for the first peak. This behavior is associated with the significant tendency of composite foams with low filler content to coalesce leading to the formation of a strongly interconnected porous structure with a high quantity of large bubbles. Vice versa, composite foams with a high filler content 
strongly limit the coalescence phenomena between the bubbles, therefore progressively in the cellular structure of the foam the contribution linked to small bubbles (first peak) becomes more relevant.

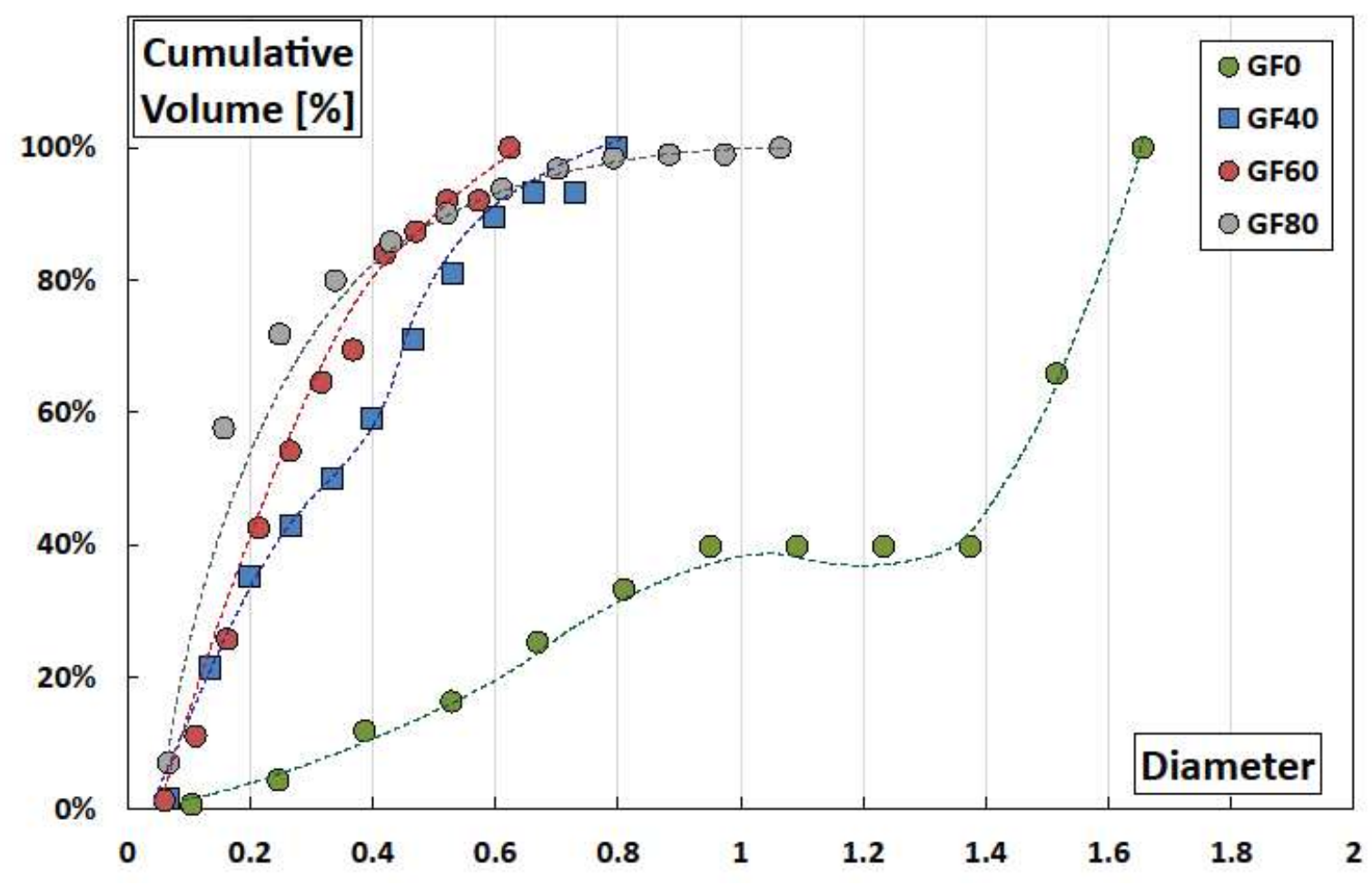

Figure 7 - Cumulative volume evolution at varying diameter for four reference composite foams at varying glass content.

Figure 7 shows the cumulative volume percentage evolution at varying diameter for all composite foams. The addition of glass powder in the siloxane foam induces a significant translation of curves toward smaller diameters. Glass filled foams (GF-40, GF-60 and GF-80) showed a quite similar trend. For these samples, the cumulative area curve starts lower cell size dimension than GF-0 batch. The unfilled foam trend is characterised by three linear sections. The first section is mainly related to small size bubbles not coalesced. Its incidence reaches about $40 \%$ of cumulative area beyond a plateau was identified. Bubble size in the range 0.9-1.4 not give a contribute in the cumulative volume. This indicates that no bubbles with this dimension were observed. Afterwards, the region with cumulative volume in the $40 \%-100 \%$ range is associated with bubble size about $1.5-1.7 \mathrm{~mm}$. As discussed above, 
this stage can be associated with the coalescence phenomena among bubbles clusters possible generating interconnected local structures. Further useful information can be acquired by analysing the evolution of the cumulative volume for GF-80 sample. The curve shows a linear trend up to a diameter of about $0.3 \mathrm{~mm}$. Afterward, a progressive deflection of the curve at increasing bubble size diameter was observed. The slope reduction found at large cell size indicate that the bubbles with alarge size have gives a lower contribute in the cumulative volume. This trend is confirmed by the stabilization of the curve for diameters above 0.8 , indicating that that coalescence is inhibited

335 It is worth stating that foams with intermediate filler content, (GF-40) evidenced a cumulative volume trend identifiable, qualitatively, as a combination between GF-0 and GF-80 foams. A slight plateau at about $0.4 \mathrm{~mm}$ indicate a threshold value that separate the two bimodal colonies of bubbles: a first cluster of bubble with size in the range 0.1-0.35 $\mathrm{mm}$ and a second cluster characterised by bubbles with large size (diameter in the range $0.55-0.8 \mathrm{~mm}$ ).

340 The morphometric parameters comparison among all composite foams (including porosity, dimension, distribution and shape of the cells) allowed to gain effective and valuable information on the cellular structure of the composite foam acquiring a more in-depth insights on changes in cell morphology induced by different filler content in the foam formulation. The performed microcomputed tomography analysis carried out to evaluate the effect of glass filler content on the 345 achievable porous structure of the composite foam allowed to identify threshold conditions for coalescence phenomena in foamed structure. These outcomes, coupled to the evaluation of morphological 3D images, can give a better understanding the relationship between foam synthesis and porous structure in order to find the effective solution for the formulation optimisation.

\section{Conclusions}

In this article, waste glass powder filled in a silicone foam at different weight content ( in the tùrange 0 wt.\%-80 wt.\% of waste glass) were produced by dehydrogenative coupling reaction between PDMS 
and PMHS siloxane compounds. The foaming of these composite foams was assessed by 3D image analysis performed by using X-ray Micro-Tomography technique. The results evidenced that:

- The micro-tomography was, at first, applied to qualitiatively evaluate foam homogeneity and compactness. Defects and local internal voids were easily identified.

- The 3D digital image analysis was able to identify void fraction volume and cell size distribution with very high sensitivity.

- Bubble size distribution analysis evidenced a bimodal cell structures for composite foams with low filler content (GF-0 and GF-20). These class of foams showed the widest cell distribution. Otherwise, the foams with very high filler content (GF-80), characterised by some heterogeneities, evidenced a unimodal bubble size distribution. An homogeneous bubble size distribution with spheroidal shaped cells was identified for intermediate composite foams (GF-60 and GF-70)

- Cell population density variations with filler content were also assessed. The results indicate that, among all the characterised foams, GF-60 showed a good compromise between relatively uniform cellular structure with spherical-like cells and good volume void fraction

\section{Acknowledgement}




\section{References}

[1] Maire E, Buffière J-Y, Salvo L, Blandin JJ, Ludwig W, Létang JM. On the application of Xray microtomography in the field of materials science. Adv Eng Mater 2001;3:539-46. doi:10.1002/1527-2648(200108)3:8\&1t;539::AID-ADEM539\&gt;3.0.CO;2-6.

375 [2] Ferrié E, Buffière J-Y, Ludwig W, Gravouil A, Edwards L. Fatigue crack propagation: In situ visualization using X-ray microtomography and 3D simulation using the extended finite element method. Acta Mater 2006;54:1111-22. doi:10.1016/j.actamat.2005.10.053.

[3] Salvo L, Suéry M, Marmottant A, Limodin N, Bernard D. 3D imaging in material science: Application of X-ray tomography. Comptes Rendus Phys 2010;11:641-9. doi:10.1016/j.crhy.2010.12.003.

[4] Bargmann S, Klusemann B, Markmann J, Schnabel JE, Schneider K, Soyarslan C, et al. Generation of 3D representative volume elements for heterogeneous materials: A review. Prog Mater Sci 2018;96:322-84. doi:10.1016/j.pmatsci.2018.02.003.

[5] Midgley PA, Dunin-Borkowski RE. Electron tomography and holography in materials science. Nat Mater 2009;8:271-80. doi:10.1038/nmat2406.

[6] Olurin OB, Arnold M, Körner C, Singer RF. The investigation of morphometric parameters of aluminium foams using micro-computed tomography. Mater Sci Eng A 2002;328:334-43. doi:10.1016/S0921-5093(01)01809-3.

[7] Gommes CJ, Bons A-J, Blacher S, Dunsmuir JH, Tsou AH. Practical methods for measuring the tortuosity of porous materials from binary or gray-tone tomographic reconstructions. AIChE J 2009;55:2000-12. doi:10.1002/aic.11812.

[8] Elmoutaouakkil A, Salvo L, Maire E, Peix G. 2D and 3D characterization of metal foams using x-ray tomography. Adv Eng Mater 2002;4:803-7. doi:10.1002/1527- 
395 [9] Buffiere J-Y, Maire E, Adrien J, Masse J-P, Boller E. In situ experiments with X ray tomography: An attractive tool for experimental mechanics. Exp Mech 2010;50:289-305. doi:10.1007/s11340-010-9333-7.

[10] Scalici T, Pitarresi G, Catalanotti G, van der Meer FP, Valenza A. The Transverse Crack Tension test revisited: An experimental and numerical study. Compos Struct 2016;158. doi:10.1016/j.compstruct.2016.09.033.

[11] Amani Y, Takahashi A, Chantrenne P, Maruyama S, Dancette S, Maire E. Thermal conductivity of highly porous metal foams: Experimental and image based finite element analysis. Int J Heat Mass Transf 2018;122:1-10. doi:10.1016/j.ijheatmasstransfer.2018.01.050.

[12] Vesenjak M, Veyhl C, Fiedler T. Analysis of anisotropy and strain rate sensitivity of open-cell metal foam. Mater Sci Eng A 2012;541:105-9. doi:10.1016/j.msea.2012.02.010.

[13] Etiemble A, Adrien J, Maire E, Idrissi H, Reyter D, Roué L. 3D morphological analysis of copper foams as current collectors for Li-ion batteries by means of X-ray tomography. Mater Sci Eng B Solid-State Mater Adv Technol 2014;187:1-8. doi:10.1016/j.mseb.2014.04.006.

410 [14] Bock J, Jacobi AM. Geometric classification of open-cell metal foams using X-ray microcomputed tomography. Mater Charact 2013;75:35-43. doi:10.1016/j.matchar.2012.10.001.

[15] Montminy MD, Tannenbaum AR, MacOsko CW. The 3D structure of real polymer foams. J Colloid Interface Sci 2004;280:202-11. doi:10.1016/j.jcis.2004.07.032.

[16] Nacucchi M, De Pascalis F, Scatto M, Capodieci L, Albertoni R. Structural analysis of advanced polymeric foams by means of high resolution X-ray computed tomography. AIP Conf Proc 2016;1749:020009. doi:10.1063/1.4954492.

[17] Chen Y, Das R, Battley M. An approach for characterising cellular polymeric foam structures using computed tomography. AIP Conf Proc 2018;1932:020002. doi:10.1063/1.5024146. 
[18] Pardo-Alonso S, Solórzano E, Brabant L, Vanderniepen P, Dierick M, Van Hoorebeke L, et al. 3D Analysis of the progressive modification of the cellular architecture in polyurethane nanocomposite foams via X-ray microtomography. Eur Polym J 2013;49:999-1006. doi:10.1016/j.eurpolymj.2013.01.005.

[19] Shahi P, Behravesh AH, Rasel S, Rizvi G, Pop-Iliev R. Morphological analysis of foamed HDPE/LLDPE blends by x-ray micro-tomography: Effect of blending, mixing intensity and foaming temperature. Cell Polym 2017;36:221-50.

[20] Sadek E, Fouad NA. Finite element modeling of compression behavior of extruded polystyrene foam using X-ray tomography. J Cell Plast 2013;49:161-91. doi:10.1177/0021955X13477436.

[21] Horpibulsuk S, Wijitchot A, Nerimitknornburee A, Shen SL, Suksiripattanapong C. Factors 430 influencing unit weight and strength of lightweight cemented clay. Q J Eng Geol Hydrogeol 2014;47:101-9. doi:10.1144/qjegh2012-069.

[22] Wang G, Liu Y, Cui Y. Performance studies of lightweight concrete mixtures made with rigid polyurethane foam wastes. Appl Mech Mater 2012;204-208:4007-10. doi:10.4028/www.scientific.net/AMM.204-208.4007.

435 [23] Tuan BLA, Hwang CL, Lin KL, Chen YY, Young MP. Development of lightweight aggregate from sewage sludge and waste glass powder for concrete. Constr Build Mater 2013;47:3349. doi:10.1016/j.conbuildmat.2013.05.039.

[24] Mohajerani A, Vajna J, Cheung THH, Kurmus H, Arulrajah A, Horpibulsuk S. Practical recycling applications of crushed waste glass in construction materials: A review. Constr Build Mater 2017;156:443-67. doi:10.1016/j.conbuildmat.2017.09.005.

[25] Calabrese L, Bonaccorsi L, Bruzzaniti P, Freni A, Proverbio E. Morphological and functional aspects of zeolite filled siloxane composite foams. J Appl Polym Sci 2018;135:45683. 
doi:10.1002/app.45683.

[26] Bumanis G, Bajare D, Locs J, Korjakins A. Alkali-silica reactivity of foam glass granules in structure of lightweight concrete. Constr Build Mater 2013;47:274-81. doi:10.1016/j.conbuildmat.2013.05.049.

[27] Blengini GA, Busto M, Fantoni M, Fino D. Eco-efficient waste glass recycling: Integrated waste management and green product development through LCA. Waste Manag 2012;32:1000-8. doi:10.1016/j.wasman.2011.10.018.

450 [28] Blengini GA, Di Carlo T. The changing role of life cycle phases, subsystems and materials in the LCA of low energy buildings. Energy Build 2010;42:869-80. doi:10.1016/j.enbuild.2009.12.009.

[29] Brancato V, Calabrese L, Palomba V, Frazzica A, Fullana-puig M, Solé A, et al. MgSO $4 \cdot 7 \mathrm{H}$ $2 \mathrm{O}$ fi lled macro cellular foams : An innovative composite sorbent for thermo-chemical energy storage applications for solar buildings 2018;173:1278-86. doi:10.1016/j.solener.2018.08.075.

[30] Piperopoulos E, Calabrese L, Mastronardo E, Proverbio E, Milone C. Synthesis of reusable silicone foam containing carbon nanotubes for oil spill remediation. J Appl Polym Sci 2018;135:46067. doi:10.1002/app.46067.

460 [31] Calabrese L, Bruzzaniti LBP, Freni AFA. Adsorption performance and thermodynamic analysis of SAPO - 34 silicone composite foams for adsorption heat pump applications. Mater Renew Sustain Energy 2018;7:24. doi:10.1007/s40243-018-0131-y.

[32] Kawai T, Tsutsumi K. Reactivity of silanol groups on zeolite surfaces. Colloid Polym Sci 1998;276:992-8. doi:10.1007/s003960050338. 
siloxane composite foams: Compression property. J Appl Polym Sci 2018;135:46145. doi:10.1002/app.46145.

[34] Moreno-Atanasio R, Williams RA, Jia X. Combining X-ray microtomography with computer simulation for analysis of granular and porous materials. Particuology 2010;8:81-99. doi:10.1016/j.partic.2010.01.001.

[35] Stock SR. Recent advances in X-ray microtomography applied to materials. Int Mater Rev 2008;53:129-81. doi:10.1179/174328008X277803.

[36] Maire E, Withers PJ. Quantitative X-ray tomography. Int Mater Rev 2014;59:1-43. doi:10.1179/1743280413Y.0000000023.

475 [37] Schümann M, Günther S, Odenbach S. The effect of magnetic particles on pore size distribution in soft polyurethane foams. Smart Mater Struct 2014;23:075011. doi:10.1088/0964-1726/23/7/075011.

[38] Kashyap YS, Yadav PS, Roy T, Sarkar PS, Shukla M, Sinha A. Laboratory-based X-ray phase-contrast imaging technique for material and medical science applications. Appl Radiat Isot 2008;66:1083-90. doi:10.1016/j.apradiso.2007.12.008.

[39] Solórzano E, Pinto J, Pardo S, Garcia-Moreno F, Rodriguez-Perez MA. Application of a microfocus X-ray imaging apparatus to the study of cellular polymers. Polym Test 2013;32:321-9. doi:10.1021/ja00855a607.

[40] Calabrese L, Bonaccorsi L, Freni A, Proverbio E. Synthesis of SAPO-34 zeolite filled macrocellular foams for adsorption heat pump applications: A preliminary study. Appl Therm Eng 2017;124:1312-8. doi:10.1016/j.applthermaleng.2017.06.121.

[41] Gibson LJ, Ashby MF. Cellular solids, structure and properties. (2nd ed). Cambridge (UK): Cambridge University Press; 1999. 
[42] Eren T. Foam Characterization: Bubble Size and Texture Effects. Middle East Technical University, 2004.

[43] Seguineau De Preval E, Fabrice D, Gilles M, Gérard C, Samir M. Influence of surface properties and bulk viscosity on bubble size prediction during foaming operation. Colloids Surfaces A Physicochem Eng Asp 2014;442:88-97. doi:10.1016/j.colsurfa.2013.05.025.

[44] Wilderjans E, Luyts A, Brijs K, Delcour JA. Ingredient functionality in batter type cake making. Trends Food Sci Technol 2013;30:6-15. doi:10.1016/j.tifs.2013.01.001.

[45] Calabrese L, Bonaccorsi L, Freni A, Proverbio E. Silicone composite foams for adsorption heat pump applications. Sustain Mater Technol 2017;12:27-34. doi:10.1016/j.susmat.2017.04.002.

500 [2] Ferrié E, Buffière J-Y, Ludwig W, Gravouil A, Edwards L. Fatigue crack propagation: In situ visualization using X-ray microtomography and 3D simulation using the extended finite element method. Acta Mater 2006;54:1111-22. doi:10.1016/j.actamat.2005.10.053.

[3] Salvo L, Suéry M, Marmottant A, Limodin N, Bernard D. 3D imaging in material science: Application of X-ray tomography. Comptes Rendus Phys 2010;11:641-9. doi:10.1016/j.crhy.2010.12.003.

[4] Bargmann S, Klusemann B, Markmann J, Schnabel JE, Schneider K, Soyarslan C, et al. Generation of 3D representative volume elements for heterogeneous materials: A review. Prog Mater Sci 2018;96:322-84. doi:10.1016/j.pmatsci.2018.02.003.

[5] Midgley PA, Dunin-Borkowski RE. Electron tomography and holography in materials 510 science. Nat Mater 2009;8:271-80. doi:10.1038/nmat2406.

[6] Olurin OB, Arnold M, Körner C, Singer RF. The investigation of morphometric parameters 
of aluminium foams using micro-computed tomography. Mater Sci Eng A 2002;328:334-43. doi:10.1016/S0921-5093(01)01809-3.

[7] Gommes CJ, Bons A-J, Blacher S, Dunsmuir JH, Tsou AH. Practical methods for measuring the tortuosity of porous materials from binary or gray-tone tomographic reconstructions. AIChE J 2009;55:2000-12. doi:10.1002/aic.11812.

[8] Elmoutaouakkil A, Salvo L, Maire E, Peix G. 2D and 3D characterization of metal foams using x-ray tomography. Adv Eng Mater 2002;4:803-7. doi:10.1002/15272648(20021014)4:10\&1t;803::AID-ADEM803\&gt;3.0.CO;2-D.

520 [9] Buffiere J-Y, Maire E, Adrien J, Masse J-P, Boller E. In situ experiments with X ray tomography: An attractive tool for experimental mechanics. Exp Mech 2010;50:289-305. doi:10.1007/s 11340-010-9333-7.

[10] Scalici T, Pitarresi G, Catalanotti G, van der Meer FP, Valenza A. The Transverse Crack Tension test revisited: An experimental and numerical study. Compos Struct 2016;158. doi:10.1016/j.compstruct.2016.09.033. 


\section{Figure Caption}

Figure 1 - example of a 3D Reconstruction (glass foam loaded with $20 \%$ of filler..........................5

Figure 2 - Transaxsial (lower left images), sagittal (right images) and coronal (top images) sections

530 for increasing glass content: (a) $0 \mathrm{wt} \%$; (b) $20 \% \mathrm{wt}$; (c) $40 \mathrm{wt} \%$; (d) $50 \mathrm{wt} \%$; (e) $60 \mathrm{wt} \%$; (f) 70

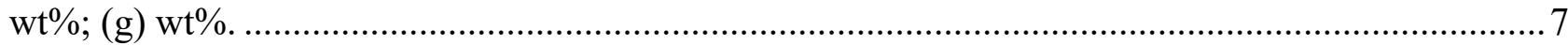

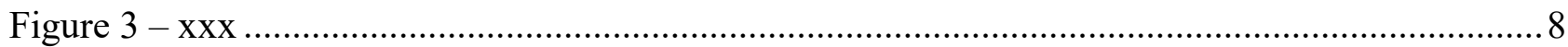

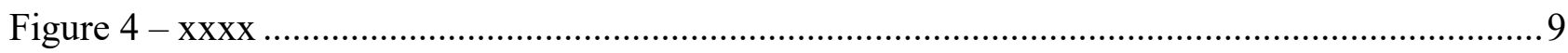

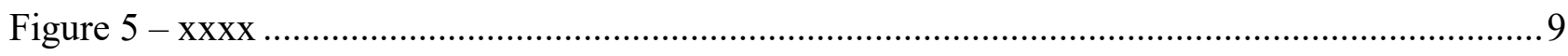

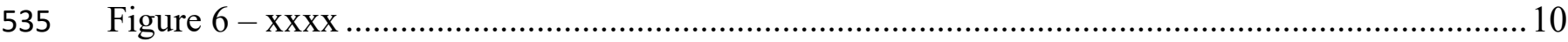

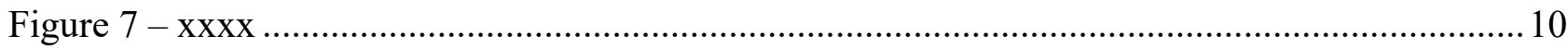

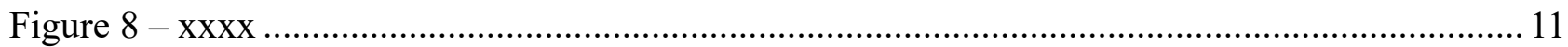




\section{Table captions}

Table 1 - Silozane solution compositions at varyng glass content ............................................. 4 